\title{
Tranexamic acid use in simultaneous bilateral total knee arthroplasty : a comparison of intravenous and intra-articular applications, which is more effective?
}

\author{
Alpaslan Öztürk, Yavuz Akalın, Nazan Çevik, Özgür Avci, Oğuz ÇEtin, Harun SaĞLICAK
}

From the Health Sciences University, Bursa Yüksek Ihtisas Research and Training Hospital Department of Orthopedics and Traumatology, Yıldırım, Bursa, Turkey

Patients applied with simultaneous bilateral total knee arthroplasty (SBTKA) with the administration of intravenous or intra-articular tranexamic acid (TXA) were compared in respect of blood loss and the need for allogenic blood transfusion.

Of a total 53 patients applied with SBTKA, 32(60\%) were administered intravenous TXA and 21(40\%) intra-articular TXA. The patients were evaluated in respect of age, gender, height, weight, body mass index (BMI), body blood volume, preoperative and $1,2,3$ and 4 days postoperative levels of hemoglobin ( $\mathrm{Hb})$ and hematocrit (Htc) and the change in $\mathrm{Hb}$ levels, estimated blood loss, mean actual blood loss, the need for allogenic blood transfusion (ABT) and the use or not of a drain.

No difference was determined between the intravenous and intra-articular groups in respect of mean age, gender, height, weight, and body blood volume. No difference was determined between the groups in preoperative and postoperative mean $\mathrm{Hb}$ and $\mathrm{Hct}$ values, the reduction in mean $\mathrm{Hb}$ postoperatively, estimated blood loss, or the need for ABT. No deep vein thrombosis or pulmonary embolism was determined in any patient.

In the application of SBTKA, TXA can be safely administered by the intravenous or intra-articular route to reduce the need for $A B T$. The results of this study determined no difference in efficacy between the routes of application. For patients with a risk of intravenous use, intra-articular application can be preferred.
Keywords : simultaneous bilateral total knee arthroplasty ; blood loss ; allogeneic blood transfusion ; intraarticular ; intravenous ; tranexamic acid.

\section{INTRODUCTION}

Blood loss (BL) after TKA has been reported as $1685.0 \pm 571.4 \mathrm{~mL}$ and need for allogenic blood transfusion (ABT) at a rate of $23 \%$ (1). As the

- Alpaslan Öztürk,

- Yavuz Akalin,

- Nazan Çevik,

- Özgür Avc1,

- Oğuz Çetin,

- Harun Sağlicak.

Health Sciences University, Bursa Yüksek Ihtisas Research and Training Hospital Department of Orthopedics and Traumatology, Yıldırım, Bursa, Turkey.

Correspondence : Alpaslan Öztürk, Professor of Orthopaedics and Traumatology, Health Sciences University, Bursa Yüksek Ihtisas Research and Training Hospital, Department of Orthopedics and Traumatology, 16310 Y1ldirım, Bursa, Turkey, Orcid: 0000-0001-7362-0284. Phone : +905323531031. Fax: +902242955497.

Email : ozturkalp16@gmail.com - alpaslan.ozturk@sbu. edu.tr

- 2021, Acta Orthopædica Belgica. 
vast majority of the patient population for TKA is $>65$ years, BL tolerance is lower because of cardiovascular diseases (2). Complications of ABT such as increased cost, blood-borne and periprosthetic joint infections, febrile and allergic reactions, hemolysis, immunosuppression, circulatory overload, electrolyte imbalance, acid-based disorders, pulmonary problems and even death, could obviously result in higher rates (3-5).

To reduce $\mathrm{BL}$ and $\mathrm{ABT}$, tranexamic acid (TXA) usage, which inhibits fibrinolysis with reversible lysine blockage without increasing thromboembolic complications, has come widespread in recent years (6). In studies showing that TXA reduced BL and ABT, successful results have been reported, but timing, route and dosage of TXA show great diversity (7-11). Intra-articular (IA) versus intravenous (IV) methods have also been studied but no difference has been determined in terms of diminishing ABT and BL (12).

Although studies related to the use of both IVTXA and IATXA and combined use in both unilateral and SBTKA have reported decreased BL and $\mathrm{ABT}$, conflicting results have been reported related to administration route $(9,11,13,14)$. There are 2 studies that reported the results of IVTXA or IATXA in SBTKA $(15,16)$. One of them reported no difference but, it was a computer assisted SBTKA and additional to this, patients with a past history of thromboembolic episodes, cerebrovascular diseases, and chronic renal diseases were excluded from this study (15). On the contrary, authors of the other one concluded IA administration was better than IVTXA in reducing blood loss and clinical outcome after SBTKA. But they also excluded patients with coagulapathy, history of thromboembolic disease, renal insufficiency (16). It has been thought that TXA could increase thromboembolic events such as deep vein thrombosis (DVT) and pulmonary emboli (PE) because of potential hypercoagulability in situations where thromboprophylactic agents cannot be used (17). Due to this theoretical risk of vascular thrombosis, an empirical trend towards not giving TXA to patients with a previous history or increased risk of DVT/PE, stroke, MI, cardiac stents or bypass surgery, or who have thrombophilia has existed (18). Hovewer, considering the beneficial effect of TXA in reducing $\mathrm{BL}$ and $\mathrm{ABT}$, we have started using IATXA instead of not using TXA for these patients with bypass surgery or vascular stent, stroke or MI, end stage renal disease and a history of DVT. As it is seen, there is no study on the use of TXA in SBTKA patients with a history of thromboembolism and the above mentioned comorbidities and there is also no consensus on the route of administration of TXA in SBTKA and the information on this subject is insufficient in the literature. For these reasons, BL and ABT were evaluated in SBTKA patients without a history of thromboembolism and who were given IVTXA, and SBTKA patients who had a history of thromboembolism, chronic renal failure, vascular stent and stroke who received IATXA in this study.

\section{MATERIALS AND METHODS}

Data of patients who underwent cemented SBTKA using IVTXA or IATXA to reduce postoperative BL and the need for ABT in our clinic between 2014 and 2019 were evaluated retrospectively. Patients with a history of bypass surgery or vascular stent, stroke or MI, end stage renal disease and a history of DVT were administered IATXA and constituted the IA group and the others who were administered IVTXA constituted the IV group. We did not exclude any patients with a history of those mentioned disorders. So, a total of 53 patients were identified who underwent SBTKA, of which 32 (60\%) were given IVTXA and 21 (40\%) were given IATXA. Approval for the study was granted by the Local Ethics Committee.

The patients were evaluated in respect of demographic characteristics [age, gender, height $(\mathrm{H})$, weight $(\mathrm{W})$, body mass index (BMI), body blood volume (BBV)], and preoperative and 1st, 2nd, 3rd, and 4th days postoperative hemoglobin $\mathrm{(Hb}$ ) and hematocrit ( $\mathrm{Htc}$ ) levels, the change in $\mathrm{Hb}$ level, estimated BL, mean actual BL, the need for ABT. Preoperative $\mathrm{Hb}$ levels were not $<10.0$ in any patient. The perioperative BL was measured using the formula described by Nadler (19). According to Nadler's formula, we first calculated the estimated BBV separately for men and female.

$B B V$-male $(L)=\left(0,3669 \times H^{3}\right)+(0,03219 \times \mathrm{W})+$ 0,6041 
$B B V$-female $(L)=\left(0,3561 \quad x \quad H^{3}\right)+(0,03308 \quad x$ W) $+0,1833$

$\mathrm{Hb}$ loss was found by applying the estimated $\mathrm{BBV}$, preoperative $\mathrm{Hb}$, postoperative $\mathrm{Hb}$ and transfused $\mathrm{Hb}$ amount to the formula below.

$\mathrm{Hb}$ loss $=$ BBVx (Preoperative Hb-Postoperative $\mathrm{Hb}) \times 10 \mathrm{dL} / \mathrm{L}+$ amount of transfused $\mathrm{Hb}$

Theoretical BL and actual BL were found by calculating the $\mathrm{Hb}$ loss, preoperative $\mathrm{Hb}$, and transfused blood volume as formulated below.

Theoretical $B L=100 \quad m L / d L x(H b \quad$ loss/Preoperative $H b$ )

Actual BL=Theoretical BL + Transfused Blood Volume

For patients with IVTXA, an infusion was administered of $15 \mathrm{mg} / \mathrm{kg}$ in $500 \mathrm{cc}$ saline $15 \mathrm{mins}$ before skin incision for $30 \mathrm{mins}$, and at 4 hours postoperatively, an infusion of $10 \mathrm{mg} / \mathrm{kg}$ in 500 cc saline for 30 mins. IATXA was administered to the proximal-medial surface of the patella with an injection after capsular closure before tourniquet deflation. IATXA was given as $1.5 \mathrm{~g}$ per knee. We have $250 \mathrm{mg} / 5 \mathrm{~mL}$ ampoules, and we filled 6 of them into a syringe and emptied them at $1.5 \mathrm{~g}$ TXA per knee.

We have not used hemovac drain for 2 years in TKA with TXA. Therefore, of the 53 cases in the study, hemovac drain was used in $30(56 \%)$ cases and not in $23(44 \%)$ cases. The operations were performed by the same surgeon. Following capsular closure of the first side TKA, before tourniquet deflation, the other knee was started. Operations were performed with regional anaesthesia under a pneumatic tourniquet $(\leq 250 \mathrm{~mm} / \mathrm{Hg})$. Femoral canal was filled with a bone plug. Cemented PS TKA was implanted. In patients with hemovac drain, after IATXA, the drain was clamped and opened 2 hours later. Patients were encouraged to start exercises in bed, and mobilized on postoperative day 1. For DVT prophylaxis, $0.4 \mathrm{ml}$ enoxaparin sodium was started 8 hours after surgery and used 10 days postoperatively. Hb level of $8.0 \mathrm{~g} / \mathrm{dl}$ was determined as trigger for ABT but transfusion was also done when $\mathrm{Hb}$ values were $8-10 \mathrm{~g} / \mathrm{dl}$ in patients with symptoms of hypotension, tachycardia, dizziness and loss of balance. Patients were discharged on postoperative day 3 with the exception of 2 patients who received $\mathrm{ABT}$ and were hospitalized for $>7$ days.

Patients with increased leg circumference, swelling and Homan's test positivity in the postoperative period were investigated with venous Doppler USG for the presence of DVT. The presence of any findings such as wound problem, hyperemia, temperature increase or sensitivity in the joint were recorded.

Data were analysed with SPSS 15.0 for Windows. Descriptive statistics were stated as number (n) and percentage $(\%)$ for categorical variables and as mean \pm sd, minimum and maximum values for numerical variables. In the comparison of two groups, Student's t-test was used for numerical variables showing normal distribution, and the Mann Whitney U-test for variables not showing normal distribution. Ratios in the groups were compared with Chi-square analysis. Significance level was accepted as 0.05 .

Table I. - Age, gender, weight, height, BMI, body blood volume values of local and systemic groups

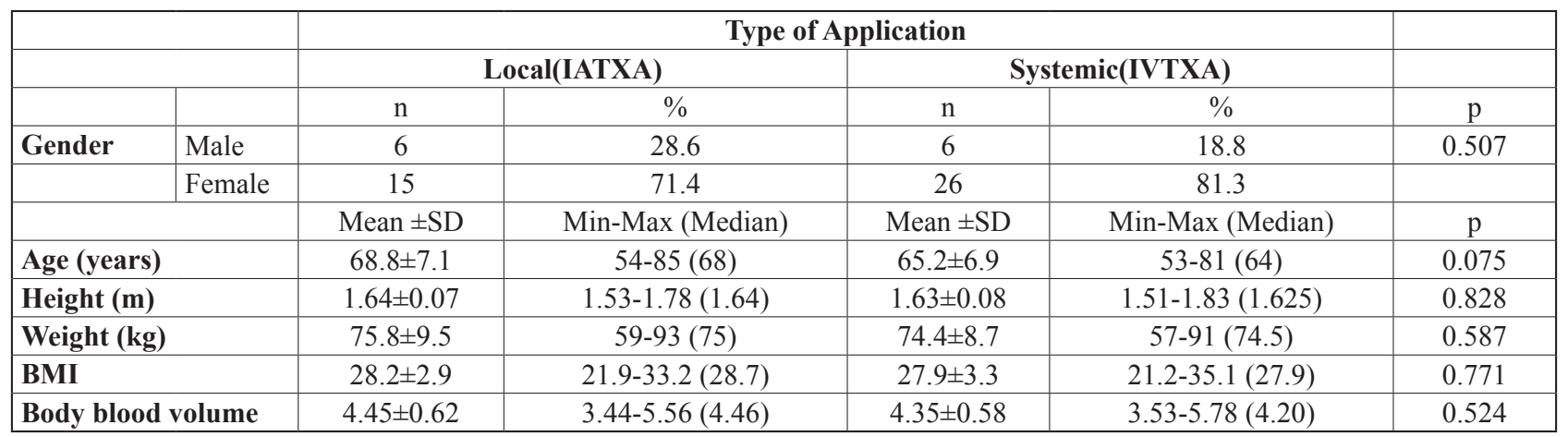




\section{RESULTS}

No difference was determined between the IVTXA and IATXA groups in respect of age, gender, height, weight, BMI and BBV (Table I). According to the American Society of Anesthesiologists (ASA) classification, there were 6 (18.8\%) ASA-1, 22 $(68.8 \%)$ ASA-2, and $4(12.5 \%)$ ASA-3 patients in the IVTXA group. In the IATXA group, there were $3(14.3 \%)$ ASA-1, 13 (61.9\%) ASA-2, 4 (19.0\%) ASA-3, 1 (4.8\%) ASA-4 patients. There was no significant difference between the groups in terms of ASA classification $(p=0,651)$. When the evaluation was made in terms of comorbidities between the IVTXA and IATXA groups, no significant difference was found between the groups (Table II). In the comparison of the TXA administration route, hemovac drain was not used in 13 patients (26 knees) applied with IVTXA and in 10 patients (20 knees) applied with IATXA. No difference was determined between the groups in respect of drain use $(p=0.615)$. No difference was determined

Table II. - Comorbidities of local and systemic TXA groups

\begin{tabular}{|l|c|c|c|}
\hline Comorbidities & $\begin{array}{c}\text { Systemic } \\
\text { (IVTXA) }\end{array}$ & $\begin{array}{c}\text { Local } \\
\text { (IATXA) }\end{array}$ & P value \\
\hline $\begin{array}{l}\text { Coronary artery } \\
\text { disease }\end{array}$ & $0(\% 0,0)$ & $2(\% 9,5)$ & 0,152 \\
\hline $\begin{array}{l}\text { Chronic renal } \\
\text { failure }\end{array}$ & $0(\% 0,0)$ & $1(\% 4,8)$ & 0,396 \\
\hline $\begin{array}{l}\text { Coronary artery } \\
\text { surgery }\end{array}$ & $0(\% 0,0)$ & $2(\% 9,5)$ & 0,152 \\
\hline Anemia & $1(\% 3,1)$ & $1(\% 4,8)$ & 1,000 \\
\hline $\begin{array}{l}\text { Hypertension } \\
\text { disease }\end{array}$ & $15(\% 46,9)$ & $12(\% 57,1)$ & 0,465 \\
\hline Diabetes mellitus & $6(\% 18,8)$ & $3(\% 14,3)$ & 1,000 \\
\hline Thyroid diseases & $4(\% 12,5)$ & $1(\% 4,8)$ & 0,637 \\
\hline Lung diseases & $6(\% 18,8)$ & $4(\% 19,0)$ & 1,000 \\
\hline $\begin{array}{l}\text { Psychiatric } \\
\text { disorders }\end{array}$ & $2(\% 6,3)$ & $2(\% 9,5)$ & 1,000 \\
\hline Hyperlipidemia & $0(\% 0,0)$ & $2(\% 9,5)$ & 0,152 \\
\hline $\begin{array}{l}\text { Rheumatoid } \\
\text { arthritis }\end{array}$ & $0(\% 0,0)$ & $2(\% 9,5)$ & 0,152 \\
\hline $\begin{array}{l}\text { Peripheral venous } \\
\text { insufficiency }\end{array}$ & $1(\% 3,1)$ & $1(\% 4,8)$ & 1,000 \\
\hline $\begin{array}{l}\text { Previous } \\
\text { gastrointestinal } \\
\text { surgery }\end{array}$ & $2(\% 6,3)$ & $5(\% 23,8)$ & 0,099 \\
\hline Others & $2(\% 6,3)$ & $5(\% 23,8)$ & 0,099 \\
\hline
\end{tabular}

in preoperative and postoperative mean $\mathrm{Hb}$, the reduction in mean $\mathrm{Hb}$ postoperatively, estimated $\mathrm{BL}$, actual BL, or the need for ABT (Table III). A total of 13 units (U) ABT were applied to 8 (38.1\%) patients in the IATXA group ( 2 patients $1 \mathrm{U}, 5$ patients $2 \mathrm{U}, 1$ patient $3 \mathrm{U})$, and a total of $8 \mathrm{U}$ to $6(18.8 \%)$ patients in the IVTXA group (4 patients 1U, 2 patients $2 \mathrm{U}$ ).

Venous Doppler USG examination was made in 5 patients in the IVTXA and 6 patients in the IATXA groups because of suspicion of DVT. No DVT or PE was determined in any patient. No revision was done in any knee because of superficial or deep infection. There was no wound problem in the follow-up of the patients.

We had 2 patients who received $\mathrm{ABT}$ and were hospitalized for $>7$ days. One of the patients was an elderly 67-year-old male patient with a history of left nephrectomy for renal failure. He was in IATXA group. Because his preoperative $\mathrm{Hb}$ value of $13.5 \mathrm{~g} /$ $\mathrm{dL}$ dropped to the level of 6.6 on the postoperative $1^{\text {st }}$ day, $2 \mathrm{U}$ ES transfusion was performed. The $\mathrm{Hb}$ level was 9 on $2^{\text {nd }}$ and $9.23^{\text {rd }}$ postoperative day. There was no problem in the mobilization of the patient and no additional problems developed. Other patient was a 76-year-old female patient who was administered IVTXA. Her Hb level was $11 \mathrm{~g} /$ $\mathrm{dL}$ before the operation. It was 10.5 on the $1^{\text {st }}, 8.5$ on the $2^{\text {nd }}$ and 7.5 on the $3^{\text {rd }}$ postoperative day, $2 \mathrm{U}$ ES transfusion was performed because of $\mathrm{Hb}$ drop. $\mathrm{Hb}$ increased to $8.7 \mathrm{~g} / \mathrm{dL}$ after ABT. Upon detection of a Felix Type 1 intraoperative fracture in the left tibia, it was fixed with 2 cannulated screws. For this reason, the patient was hospitalized for more than 7 days in order to learn about controlled rehabilitation. The postoperative course was uneventful.

\section{DISCUSSION}

Although TXA has been used to reduce BL and the need for ABT in SBTKA, no consensus has yet been reached on the ideal administration route (1,9,20-22). The most significant finding of this study was that there was no difference between IVTXA and IATXA in SBTKA in respect of the amount of $\mathrm{BL}$ and the need for ABT. A secondary outcome was that in drainless SBTKA, there was advantage of either of the two routes of TXA. The results of the 
Table III. — Local and systemic TXA preoperative and postoperative blood values, blood losses need for blood transfusion

\begin{tabular}{|c|c|c|c|c|c|c|}
\hline & & \multicolumn{4}{|c|}{ Application Type } & \multirow[b]{3}{*}{$\mathrm{p}$} \\
\hline & & \multicolumn{2}{|c|}{ Local(IATXA) } & \multicolumn{2}{|c|}{ Systemic(IVTXA) } & \\
\hline & & Mean \pm SD & Min-Max (Median) & Mean \pm SD & Min-Max (Median) & \\
\hline \multirow[t]{6}{*}{ HGB } & Preop & $12.56 \pm 1.62$ & $9.2-15.5(12.4)$ & $12.63 \pm 1.24$ & $10.3-14.9(12.8)$ & 0.867 \\
\hline & PO 1 & $10.96 \pm 1.60$ & $6.6-14.3(10.9)$ & $11.33 \pm 1.14$ & 9.6-14.1 (11.05) & 0.418 \\
\hline & PO 2 & $10.16 \pm 1.85$ & $7-13.7(9.5)$ & $10.87 \pm 1.52$ & $8.5-14.2(11)$ & 0.134 \\
\hline & PO 3 & $9.78 \pm 1.76$ & $7.5-13.1(9.2)$ & $9.88 \pm 1.49$ & $7.5-13(10.1)$ & 0.813 \\
\hline & PO 4 & $9.66 \pm 1.70$ & $7-12.3(9)$ & $9.73 \pm 1.78$ & $7-12.6(9.45)$ & 0.985 \\
\hline & Minimum & $9.02 \pm 1.74$ & $6.6-11.9(8.3)$ & $9.33 \pm 1.43$ & $7-11.5(8.95)$ & 0.506 \\
\hline \multirow[t]{5}{*}{ HTC } & Preop & $37.6 \pm 4.8$ & $27.7-44.7(38.1)$ & $38.1 \pm 3.9$ & $30.3-45.8(38.5)$ & 0.665 \\
\hline & PO 1 & $33.8 \pm 5.2$ & $20.7-43.1(32.8)$ & $35.0 \pm 3.7$ & $28.3-42.3(33.8)$ & 0.344 \\
\hline & PO 2 & $32.2 \pm 5.3$ & $25.5-41.2(31.8)$ & $33.3 \pm 5.0$ & $25.5-42.4(33.45)$ & 0.433 \\
\hline & PO 3 & $30.9 \pm 6.3$ & $22.1-40.1(30.1)$ & $31.0 \pm 5.6$ & $22.2-39.7(31.85)$ & 0.971 \\
\hline & PO 4 & $30.6 \pm 5.9$ & $20.8-40.4(29.6)$ & $30.5 \pm 6.4$ & $20.8-40.1(31.2)$ & 0.949 \\
\hline \multicolumn{2}{|c|}{ Hemoglobin loss (gr) } & $162.2 \pm 69.3$ & $56.0-323.7(154.5)$ & $145.8 \pm 69.5$ & $37.9-305.0$ (128.9) & 0.404 \\
\hline \multicolumn{2}{|c|}{ Theoretical blood loss ( ml ) } & $1282.8 \pm 497.4$ & 462.6-2529.1 (1188.2) & $1143.1 \pm 501.4$ & $305.4-2323.5(1072.6)$ & 0.324 \\
\hline \multicolumn{2}{|c|}{ Actual blood loss ( ml ) } & $992.3 \pm 523.7$ & $-445.2-1956.1(1110.7)$ & $946.2 \pm 469.6$ & 246.7-1955.6 (917.7) & 0.740 \\
\hline \multirow{2}{*}{$\begin{array}{l}\text { Blood } \\
\text { transfusion }\end{array}$} & No & \multicolumn{2}{|r|}{$13(61.9)$} & \multicolumn{2}{|r|}{$26(81.3)$} & 0.118 \\
\hline & Yes & \multicolumn{2}{|r|}{$8(38.1)$} & \multicolumn{2}{|r|}{$6(18.8)$} & \\
\hline \multicolumn{2}{|r|}{1 Unit } & \multicolumn{2}{|r|}{$2(9.5)$} & \multicolumn{2}{|r|}{$4(12.5)$} & \\
\hline \multicolumn{2}{|r|}{2 Unit } & \multicolumn{2}{|r|}{$5(23.8)$} & \multicolumn{2}{|r|}{$2(6.3)$} & \\
\hline \multicolumn{2}{|r|}{3 Unit } & \multicolumn{2}{|r|}{$1(4.8)$} & \multicolumn{2}{|r|}{$0(0.0)$} & \\
\hline
\end{tabular}

current study show that both IATXA and IVTXA can be used in SBTKA safely.

Although less BL has been reported with combined administration of IVTXA+IATXA than single IVTXA route in a non-randomised comparative study with tourniquetless SBTKA (9), no benefit of combined administration has been found in recent prospective randomized studies in SBTKA $(1,11,20)$. These studies were all comparison of combined group vs single route of TXA administration. We did not have combined group in our study. However, there are few studies which compared the sole use of IVTXA or IATXA in SBTKA $(15,16)$. In a prospective study of 90 patients with computerassisted SBTKA were evaluated in 3 groups of placebo, $1 \mathrm{~g}$ IVTXA and $1 \mathrm{~g}$ IATXA to each knee of TXA. Although the TXA groups were seen to have better results in respect of the postoperative decline in $\mathrm{Hb}$ level and need for ABT, no superiority of one route was determined. But, this study was based on computer-assisted SBTKA (15). However, the administration of $15 \mathrm{mg} / \mathrm{kg}$ IATXA $10 \mathrm{mins}$ before closure was seen to have relatively better results compared to 2 doses of IVTXA $(15 \mathrm{mg} / \mathrm{kg}$
30 mins before tourniquet deflation, and the same dose repeated 2 hours later) in a prospective study of 70 patients (16). Additionally, patients with a history of bleeding disorders, thromboembolic episodes, cerebrovascular diseases, known allergy to TA and chronic renal or liver diseases were excluded from these above mentioned studies $(15,16)$. On the contrary, the decrease in $\mathrm{Hb}$ level in the first 4 days postoperatively was the same in IATXA and IVTXA groups in the current study. As it is seen there is no consensus on the better route of TXA administration. When combined group studies are taken into account that combined TXA administration had no advantage over sole use $(11,20)$, we suggest the IVTXA or IATXA to be appropriate for the reduction of $\mathrm{BL}$ and requirement for ABT in SBTKA despite the lack of a combined group in our study. Furthermore, we think that IATXA can be used safely in patients with a history of thromboembolism, stroke, vascular stents, CHD and chronic renal failure regarding that we had no complications related to IATXA in these patients.

There is no consensus not only the route of administration but also on the dose of TXA and 
the number of applications (21-23). IVTXA is administered either single or multiple times and the amount of dose is also controversial $(1,9,11,15,18,20,24,25)$. Single dose of $1 \mathrm{~g}$ IVTXA has been found to be ineffective when compared to patients with no IVTXA in SBTKA (26). IATXA is also administered with a variety of dosages (range, 1-3 g per knee) $(11,13,18,25)$. In a study where $1.5 \mathrm{~g}$ and $3 \mathrm{~g}$ IATXA doses were compared in unilateral TKAs, BL was determined to be reduced by $20 \%$ $(300 \mathrm{~mL})$ and $25 \%(400 \mathrm{~mL})$ respectively compared to placebo group, but no difference was found between the $1.5 \mathrm{~g}$ and $3 \mathrm{~g}$ IATXA (27). In the current study, IATXA was administered as $1.5 \mathrm{~g}$ to each knee, and IVTXA as $15 \mathrm{mg} / \mathrm{kg}$ just before skin incision $+10 \mathrm{mg} / \mathrm{kg}$ after 4 hours postoperatively. Other than the aim of comparing the TXA doses, as no difference was determined between the IVTXA and IATXA in respect of decrease in $\mathrm{Hb}$ level, BBL, and $\mathrm{ABT}$, we recommend that these doses can be used effectively in SBTKA.

Previous studies have found no difference between IVTXA and IATXA in respect of ABT (15). However, in a prospective, randomized study with SBTKA, it was reported that while ABT was not required in IATXA group, transfusion was required in 7 out of $35(20 \%)$ patients in IVTXA group, and thus IATXA administration was concluded to be more advantageous (16). In the current study, we found no significant difference between groups in respect of $\mathrm{ABT}$ which was consistent with the literature.

Venous Doppler USG was made of a total of 11 patients in the current study, 6 in IATXA and 5 in IVTXA groups, who had increased leg circumference and complaints of pain. No DVT was detemined in any patient and the postoperative rehabilitation program was continued. No PE developed clinically in any patient and no superficial or deep infection was determined in any case. IVTXA and IATXA administration in computer-assisted SBTKA have caused no difference in respect of DVT, PE, infection or wound problems (15). In a study which compared a combined IVTXA+IATXA group with a sole IVTXA in SBTKA, no thrombotic events was reported in either group, and $1(2 \%)$ patient in the IVTXA group developed arrythmia for which a pacemaker was fitted (9). In another study which compared 154 patients, distal DVT was detected in four of 43 patients $(9 \%)$ in the combined IVTXA+IATXA group and four of 34 patients $(12 \%)$ in the IVTXA group without any significance and no major thrombotic events other than distal DVT were determined between groups (20).

In a study comparing 871 patients who were given TXA at a 2-hour interval with 874 patients who were not given TXA in SBTKA, the frequency of DVT was found in $18 \%$ in the group given TXA and $14 \%$ in the control group, and no significant difference was found (25). In a randomized, controlled study, which compared IATXA only and combined IVTXA+IATXA in SBTKA, no symptomatic DVT or PE, and no superficial wound necrosis were seen in any patient, while wound leakage was observed in $6(4 \%)$ cases in the IATXA group and $5(3 \%)$ in the combined group, with no significant difference(11). TXA has been administered IV and IA in SBTKA operations and no complications have been reported (16).

In recent years, the use of a hemovac drain in TKA has been shown to increase BL and its use is not recommended since it provides no advantage (28-30). Nevertheless, the results of the cases where drain was or was not used were seen to be similar in the current study in both groups.

The main limitation of this study was the retrospective design. Major disadvantage is loss of data from patient files in retrospective studies. However, since 2011, for primary and revision arthroplasties, the data related to BL and ABT have been recorded on a pre-prepared chart in our clinic. Therefore, there were no incomplete or loss of data eliminates this disadvantage. In most studies these types of patients have been excluded, but in the current study, SBTKA patients were compared by admistering IATXA. Thus, the disadvantage of excluding patients can be considered to have been prevented.

\section{CONCLUSION}

In conclusion, when all the results are taken into consideration, TXA can be administered by $\mathrm{IV}$ or IA route to reduce $\mathrm{BL}$ and the need for $\mathrm{ABT}$ 
in SBTKA operations. In particular, as no major complications developed in patients with a history of thromboembolism, the administration of IATXA to each knee can be considered both practical and safe and can therefore be recommended.

\section{REFERENCES}

1. Cao G, Chen G, Huang Q, Huang $Z$ et al. The efficacy and safety of tranexamic acid for reducing blood loss following simultaneous bilateral total knee arthroplasty: a multicenter retrospective study. BMC Musculoskelet Disord. 2019 Jul ; 20(1) :325.

2. Friedman Z, Perel A. [Acute normovolemic hemodilution as a method of decreasing exposure to allogenic blood transfusion during surgery]. Harefuah. 2000 Sep ; 139 (56) : 207-9.

3. Kleinman S, Chan P, Robillard P. Risks associated with transfusion of cellular blood components in Canada. Transfus Med Rev. 2003 Apr ; 17(2) : 120-62.

4. Pulido L, Ghanem E, Joshi A, Purtill JJ, Parvizi J. Periprosthetic joint infection : the incidence, timing, and predisposing factors. Clin Orthop Relat Res. $2008 \mathrm{Jul}$; 466(7) : 1710-5.

5. Vamvakas EC, Blajchman MA. Transfusion-related mortality : the ongoing risks of allogeneic blood transfusion and the available strategies for their prevention. Blood. 2009 Apr 9 ; 113(15) : 3406-17.

6. Xiong H, Liu Y, Zeng Y, Wu Y, Shen B. The efficacy and safety of combined administration of intravenous and topical tranexamic acid in primary total knee arthroplasty : a meta-analysis of randomized controlled trials. BMC Musculoskelet Disord. 2018 Sep 7 ; 19(1) : 321.

7. MacGillivray RG, Tarabichi SB, Hawari MF, Raoof NT. Tranexamic acid to reduce blood loss after bilateral total knee arthroplasty : a prospective, randomized double blind study. J Arthroplasty. 2011 Jan ; 26(1) : 24-8.

8. Tanaka N, Sakahashi H, Sato E, Hirose K, Ishima T, Ishii S. Timing of the administration of tranexamic acid for maximum reduction in blood loss in arthroplasty of the knee. J Bone Joint Surg Br. 2001 Jul ; 83(5) : 702-5.

9. Tsukada S, Wakui M. Combined Intravenous and IntraArticular Tranexamic Acid in Simultaneous Bilateral Total Knee Arthroplasty without Tourniquet Use. JB JS Open Access [Internet]. 2017 Apr 18 [cited 2020 Sep 5]; 2(2). Available from : https://www.ncbi.nlm.nih.gov/pmc/ articles/PMC6132473.

10. Lee SY, Chong S, Balasubramanian D, Na YG, Kim TK. What is the Ideal Route of Administration of Tranexamic Acid in TKA? A Randomized Controlled Trial. Clin Orthop Relat Res. 2017 Aug ; 475(8) : 1987-96.

11. Meshram P, Palanisamy JV, Seo JY, Lee JG, Kim TK. Combined Intravenous and Intraarticular Tranexamic Acid Does Not Offer Additional Benefit Compared with
Intraarticular Use Alone in Bilateral TKA : A Randomized Controlled Trial. Clin Orthop Relat Res. 2020 ; 478(1) : 4554.

12. Nielsen CS, Jans Ø, Ørsnes T, Foss NB, Troelsen A, Husted H. Combined Intra-Articular and Intravenous Tranexamic Acid Reduces Blood Loss in Total Knee Arthroplasty: A Randomized, Double-Blind, PlaceboControlled Trial. J Bone Joint Surg Am. 2016 May 18; 98(10) : 835-41.

13. Karaaslan F, Karaoğlu S, Mermerkaya MU, Baktir A. Reducing blood loss in simultaneous bilateral total knee arthroplasty: combined intravenous-intra-articular tranexamic acid administration. A prospective randomized controlled trial. Knee. 2015 Mar ; 22(2) : 131-5.

14. Prieto HA, Vincent HK, Deen JT, Iams DA, Parvataneni HK. Tranexamic Acid Effectively Reduces Blood Loss and Transfusion Rates during Simultaneous Bilateral Total Knee Arthroplasty. J Knee Surg. 2018 Mar ; 31(3) : 270-6.

15. Hegde C, Wasnik S, Kulkarni S, Pradhan S, Shetty V. Simultaneous Bilateral Computer Assisted Total Knee Arthroplasty: The Effect of Intravenous or Intraarticular Tranexamic Acid. J Arthroplasty. 2013 Dec 1; 28(10) : 1888-91.

16. Aggarwal AK, Singh N, Sudesh P. Topical vs Intravenous Tranexamic Acid in Reducing Blood Loss After Bilateral Total Knee Arthroplasty: A Prospective Study. J Arthroplasty. 2016 ; 31(7) : 1442-8.

17. Alshryda S, Sarda P, Sukeik M, Nargol A, Blenkinsopp J, Mason JM. Tranexamic acid in total knee replacement : a systematic review and meta-analysis. J Bone Joint Surg Br. 2011 Dec ; 93(12) : 1577-85.

18. Maniar RN, Pradhan P, Bhatnagar N, Maniar A, Bidwai R, Bindal P. Role of Suction Drain after Knee Arthroplasty in the Tranexamic Acid Era: A Randomized Controlled Study. Clin Orthop Surg. 2019 Mar ; 11(1) : 73-81.

19. Nadler SB, Hidalgo JH, Bloch T. Prediction of blood volume in normal human adults. Surgery. 1962 Feb; 51(2) : 224-32.

20. Tsukada S, Kurosaka K, Nishino M, Maeda T, Yonekawa $\mathbf{Y}$, Hirasawa N. Intra-articular tranexamic acid as an adjunct to intravenous tranexamic acid for simultaneous bilateral total knee arthroplasty: a randomized doubleblind, placebo-controlled trial. BMC Musculoskelet Disord [Internet]. 2019 Oct 22 [cited 2020 Sep 5] ; 20. Available from : https://www.ncbi.nlm.nih.gov/pmc/articles/PMC 6805302.

21. X C, X C, C Y, K G, Q Z, J Z. Effectiveness and Safety of Fixed-Dose Tranexamic Acid in Simultaneous Bilateral Total Knee Arthroplasty: A Randomized Double-Blind Controlled Trial [Internet]. Vol. 31, J Arthroplasty ; 2016 [cited 2020 Sep 5]. Available from : https : //pubmed.ncbi. nlm.nih.gov/27167769.

22. Fu Y, Shi Z, Han B, Ye Y, You T, Jing J, et al. Comparing efficacy and safety of 2 methods of tranexamic acid administration in reducing blood loss following total knee arthroplasty : A meta-analysis. Medicine (Baltimore). 2016 2016 Dec ; 95(50) : e5583. 
23. Lin C, Qi Y, Jie L, Li H, Zhao X, Qin L, et al. Is combined topical with intravenous tranexamic acid superior than topical, intravenous tranexamic acid alone and control groups for blood loss controlling after total knee arthroplasty. Medicine (Baltimore) [Internet]. 2016 Dec 23 [cited 2020 Sep 5];95(51). Available from: https:// www.ncbi.nlm.nih.gov/pmc/articles/PMC5181805.

24. Mutsuzaki H. Effect of Injecting Tranexamic Acid from a Drain to the Joint and Drain-Clamping to Reduce Blood Loss during Bilateral Cementless Total Knee Arthroplasty. $2014 ; 5(4): 4$.

25. Kim Y-H, Park J-W, Kim J-S, Seo D-H. Does tranexamic acid increase the risk of thromboembolism after bilateral simultaneous total knee arthroplasties in Asian Population? Arch Orthop Trauma Surg. 2018 Jan ; 138(1) : 83-9.

26. Mukherjee S, Tripathy SK, Maiti R, Nayak C, Samal BP, Rao B, et al. Single dose Intravenous Tranexamic acid may not be adequate to reduce blood loss and blood transfusion requirement in patients undergoing single stage bilateral total knee arthroplasty. Acta Orthop Belg. 2019 Sep ; 85(3) : 364-72.
27. Mi B, Liu G, Zhou W, Lv H, Liu Y, Zha K, et al. Intraarticular versus intravenous tranexamic acid application in total knee arthroplasty: a meta-analysis of randomized controlled trials. Arch Orthop Trauma Surg. 2017 Jul ; 137(7) : 997-1009.

28. Wong J, Abrishami A, El Beheiry H, Mahomed NN, Roderick Davey J, Gandhi R, et al. Topical application of tranexamic acid reduces postoperative blood loss in total knee arthroplasty: a randomized, controlled trial. J Bone Joint Surg Am. 2010 Nov 3 ; 92(15) : 2503-13.

29. Demirkale I, Tecimel O, Sesen H, Kilicarslan K, Altay M, Dogan M. Nondrainage decreases blood transfusion need and infection rate in bilateral total knee arthroplasty. $J$ Arthroplasty. 2014 May ; 29(5) : 993-7.

30. Hu Y, Li Q, Wei B-G, Zhang X-S, Torsha TT, Xiao J, et al. Blood loss of total knee arthroplasty in osteoarthritis : an analysis of influential factors. J Orthop Surg Res [Internet]. 2018 Dec 22 [cited 2020 Sep 5]; 13. Available from: https://www.ncbi.nlm.nih.gov/pmc/articles/PMC6303980. 